\title{
DO THE MAEI,
}

REAP TEE REWARDS Worlaing Towards the integration of Indigenous Knowledge within Design Education

\section{Nan O'sullivan}

1. Hiniri Moko Mead, Tikanga Māori: Living by Māori Values (Wellington: Huia Publishers, 2003).

2. Nan O'Sullivan, "Walking Backwards into the Future: Indigenous Wisdom within Design Education," Educational Philosophy and Theory 51, no. 4 (2018), 424-33.

3. The Treaty of Waitangi recognizes Māori and Pākehā (white New Zealanders) as having equal rights. It is an agreement made in 1840 between representatives of the British Crown and more than five hundred Māori chiefs. Most chiefs signed a Māori-language version of the treaty that in translation held different meanings, therefore had different expectations of the terms. Resolution of these differences has presented

New Zealand with challenges and ongoing negotiations and claims throughout its history. See teara.govt.nz/en/ treaty-of-waitangi/page-1.
"Māori knowledge has come out of hiding and is now in the bright light of day." "New Zealand Māori are the indigenous peoples of New Zealand and, alongside many others from the Pacific nations, contribute to New Zealand being a bicultural nation and a multicultural society. A particular focus of this paper is the motivations, opportunities, challenges, and outcomes of efforts made to facilitate the recognition and integration of indigenous knowledge into design education within Te Kura Hoahoa, the School of Design Innovation (SODI), Te Herenga Waka, Victoria University of Wellington (VUW) in Aotearoa New Zealand. This paper is written with an understanding that indigenous knowledge is not old knowledge or knowledge relevant to distant, now-outmoded times, and a recognition that this wisdom continues to evolve through rebellious, resistant, and resilient cultural practices. ${ }^{2}$ It will illustrate efforts within Te Herenga Waka (VUW) to address our commitments to Te Tiriti o Waitangi, the Treaty of Waitangi, ${ }^{3}$ to increase the cultural competency of both staff and students, and, particularly within Te Kura Hoahoa (SODI), to recalibrate design pedagogy to better enable our staff and graduates to engage with diversity, equity, inclusivity, and sustainability. 
The efforts discussed are specific to the first-year Design and the Design for Social Innovation (DSI) programs as trailblazers for these initiatives within the school. The design profession has heard time and time again that designers are now required to understand the complexities born of diverse and often contentious cultural, societal, and global issues. ${ }^{4}$ It follows that our graduates will be required to play pivotal roles within the resolutions or interventions sought. To that end, this paper posits the need for design institutes to graduate students who can improve the discipline's capacity and capability to contribute to the development of more inclusive, equitable, sustaining, and sustainable futures and offers an overview of current efforts to achieve this within Te Kura Hoahoa, the School of Design Innovation, Te Herenga Waka, Victoria University of Wellington in Aotearoa New Zealand.

We seek to transition away from the dominant Eurocentric model of design education to a place-based pedagogy, informed by culturally inclusive principles, traditional knowledge, and strategies that hold at their core the health and well-being of both people and place - past, present, and future. Guiding our efforts within the first-year and Design for Social Innovation programs is a precolonial whakatauki (traditional Māori proverb): "Hoki whakamuri kia anga whakamua" (Let us walk backwards into the future). Informing the process is the acknowledgment of, respect for, and engagement with te ao Māori (Māori worldview), tikanga Māori (Māori protocols and values), and mātauranga Māori (Māori knowledge).

\section{our commitment: With, and as, Tangata Whenua (the people of the Land), We Value Te Tiriti 0 Waitangi ${ }^{5}$}

The Education Act 1989 requires that education providers acknowledge the broader principles of the Treaty of Waitangi in order to develop the relationship between Māori and the Crown. These principles, including equality, cooperation, and self-determination, still frame VUW's strategic goals and are viewed as distinctive qualities disseminated through tikanga Māori (Māori values), 
8. Victory University of Wellington Human Resources, Tikanga Mãori at Victoria

(Wellington: Victoria University of Wellington, 2016).

9. VUW Human Resources. mātauranga Māori (Māori knowledge), and te reo Māori (the Māori language). ${ }^{6}$ In 2014, the university reiterated this, stating that

our respect for Te Tiriti o Waitangi and mätauranga Māori motivates us to influence and inform societal change for the betterment of Aotearoa New Zealand. We embed te reo, tikanga and mätauranga Māori in our university's activities, including research, learning, and teaching. ${ }^{7}$

To further enable the fruition of these goals, Te Rautaki Maruako, the Learning and Teaching Strategy 2017-2021 (LTS), was designed. The strategy, self-described as "unreservedly ambitious," gives direction and guidance for the entire university and signals a commitment to working in partnership to create and maintain an inclusive learning and teaching environment. Outlining six tikanga (values) as its bedrock, the LTS aims to "provide a holistic learning, teaching and student experience second to none." values are akoranga (lifelong learning), whanaungatanga (collaboration), whai màtauranga (curiosity), kaitiakitanga (guardianship), manaakitanga (respect), and rangatiratanga (self-determination). Implementation of the LTS is assisted by Te Hāpai staff development program, which consists of workshops, booklets, and mentorship arrangements that are available to all staff both academic and professional. The program has been designed and is supported by the Office of the Deputy Vice-Chancellor (Māori) and aims to increase the understanding and use of Māori culture, tikanga (values), te reo (language), and the Treaty of Waitangi within the teaching, learning, and research environments. ${ }^{9}$ All staff within the School of Design, including new and international staff, are encouraged as a part of their professional development to undertake these workshops.

The uptake by design school staff has been positive, but not unrealistically, and with an appreciation that their engagement requires whakawhanaungatanga (authentic and meaningful engagement), some staff members are hesitant to use te reo for fear of mispronunciation or misuse, while the structuring of the values within the curriculum and 
course content can also need korero (discussion) and guidance from specific kaiwhakaako (guides or instructors) to ensure respectful and meaningful engagement. The guidance offered as a part of the LTS strategy and Te Hāpai have enabled the first-year and DSI programs to create a foundation and distinct pathways of integration for mātauranga Māori (Māori knowledge), te reo Māori (Māori language), and tikanga Māori (Māori values). The knowledge embedded also guides the teaching and learning relationship, delivery modes, and the content and contexts outlined within the curricula redesign. The university's investment plan contains the specific goal "to develop Māori staff capabilities and increase the ability for staff to engage with Māori." An important step towards this, and one that requires consistent consideration, strategic efforts, and reflection on one's own unconscious biases, is the visibility and presence of both Māori staff and students.

\section{Cultural Competency: "HE ReO E Rangona, Engari He Kanohi Kitea" (A Voice May Be Heard but a Eace Needs to Be Seen) ${ }^{11}$}

In 2016, the academic staff at Te Kura Hoahoa, the School of Design Innovation numbered fourteen, none of whom were of Māori or Pasifika descent, and only one staff member of color. In 2020, in line with the growth of the school's offerings, the staff and student numbers have increased considerably. There are now twenty-four academic staff, including three of Māori descent; two of these staff members are teaching in the DSI and one, a graduate of media design, is teaching in that program and the first year. The generosity shown through knowledge-sharing has been invaluable, but with the representation of Māori within the staff at 12.5 percent, considerable responsibility and an awkward imbalance is placed on a few staff to inform, guide, and "act on the behalf of" other staff members. Although many Māori competent or growing in confidence with te reo or kaupapa Māori have shown understanding and generosity, ${ }^{12}$ concerns have been expressed about, firstly, the assumption that Māori wish to do this work (a job of many which, due to the low number of Māori staff, 
13. New Zealand Government, Stats NZ (website), www.stats. govt.nz (accessed January 7 , 2020). is made the responsibility of a few) and, secondly, the lack of engagement with, and in some cases lack of respect for, kaupapa Māori by non-Māori staff.

Statistics, although a blunt tool tallying only tangible outputs, sit at the heart of any attempt to measure the movement of numbers. VUW's pursuit to increase the inclusion and integration of mātauranga Māori (Māori knowledge) has shown that within Te Kura Hoahoa, the School of Design Innovation the number of Māori students graduating sat at 10 percent in 2019. This is an increase from 5 percent in 2016 and could be linked to the inclusion of Māori on the staff, but no research has been undertaken to ascertain this. Although this is an improvement, these numbers do not yet represent the cultural diversity of New Zealand's population, the majority of which is of European descent, referred to as Pākehā (white New Zealanders), with indigenous Māori being the largest minority at 16.5 percent, closely followed by Asians at 15.35 percent and non-Māori Pacific Islanders at 9 percent. ${ }^{13}$

In 2016, the SODI's first-year cohort represented thirty-one cultures. The highest number by over three times was Pākehā. This number is followed by Asian-Pacific students, many of whom are international students and new to our shores. The two smallest groups are Māori and Pasifika students. An important finding from an online research questionnaire put to the 2016 first-year design students was that the Māori and Pasifika contingent consider Western influences to be more relevant to their studies than their own cultures' everyday customs, ideologies, or beliefs. SCHOOL OF DESIGN VICTORIA UNIVERSITY OF WELLINGTON
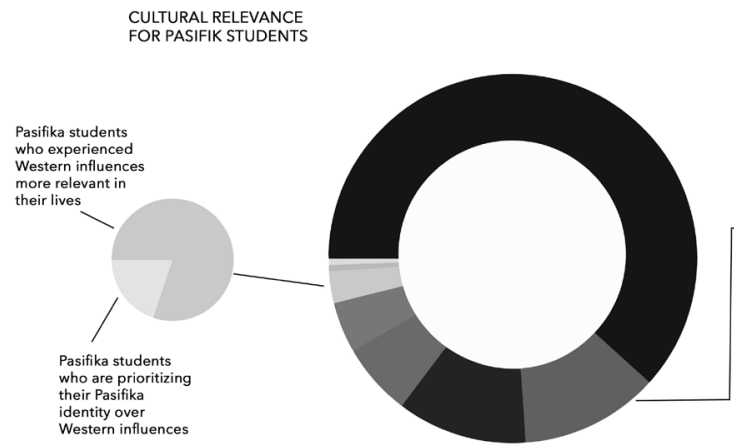

CULTURAL RELEVANCE FOR MAORI STUDENTS

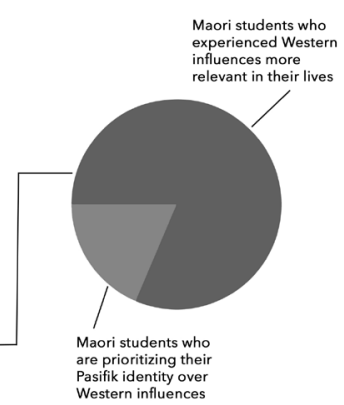


Having completed both an undergraduate degree and a master's degree at Te Kura Hoahoa, the School of Design Innovation, a student of Samoan descent, St Andrew Matautia, stated that

casting an eye over my educational experience, an epiphany had occurred when I was encouraged (although at first it felt like I was being permitted) to use aspects of my culture in my design process. There was no doubt that this inclusion allowed me to express myself, explore more confidently and design more intuitively. ${ }^{14}$

\section{"This one Storgline Is conceived from the Perspective of the Euro-American Experience and Exported to Mang World Regions over the Past Eew-Hundred Years" ${ }^{15}$}

It could be construed from ongoing critiques of design education that the lack of appropriate culturally inclusive course content or any traditional knowledge within design curricula contributes to the displacement of students who do not identify with the hegemony or homogeneity of the Eurocentric or Euro-American tenets principally assimilated through modernist edicts. In addition to this, those delivering the course content also represent, and in many cases hold steadfast to, these codified and ingrained design doctrines. Within the DSI and first-year programs we acknowledge this approach as a fundamental flaw and seek change. One of the undertakings our programs has made to enable the shift Matautia speaks of, is to consciously parallel the diversity exhibited between the students and tutors. ${ }^{16}$ In doing so, tutors and staff have also been able to shift their stance to one of learning from the student group. This ploy is synonymous with the "Silent Way," as developed by the French mathematician and educator, Caleb Gattegno (1911-1988), and employs indigenous methods of teaching and learning where the silence of the teacher gives the students room to explore cultural acumen and the teacher room to grow through observation. ${ }^{17}$
14. Nan O'Sullivan, "Constructing Your Own Reality Prevents Others from Doing It for You: A Shift towards Cultural Inclusivity in Design," Cumulus REDO Conference (Kolding: Kolding Design Academy, 2018).

15. Arturo Escobar, "Transiciones: A Space for Research and Design for Transitions to the Pluriverse," Design Philosophy Papers 13, no. 1 (2015), 13-23.

16. Every course employs tutors within the studio or tutorial group to support the staff member responsible for the course. The tutor to student ratio is one-to-eighteen in the studio. Course numbers range from approximately fifteen to three-hundred students.

17. Caleb Gattegno, The Silent Way (New York, NY: Education Solutions Worldwide, 1963). 
18. Renata Leitão,

"Recognising and Overcoming the Myths of Modernity," in

Proceedings of Design Research

Society Conference DRS 2018:

Catalyst (Limerick: University

of Limerick, 2018), 8.

19. Linda Leach, “'I Treat All Students Equal': Further and Higher Education Teachers'

Responses to Diversity,"

Journal for Further and Higher

Education 35, no. 247 (2011),

263.

20. Rawinia Higgins,

"Contributions to the Growth

and Development of Māori

Matauranga," Enriching

Cultural Heritage Symposium

(Wellington: Te Herenga

Waka, Victoria University of

Wellington, 2016).

21. Irwin, "Transition Design Provocation."

22. O'Sullivan, "Constructing Your Own Reality Prevents Others from Doing It for You."

23. Jamie Gamble et al., "Theme 4: Evidence for Innovation," The Royal

Children's Hospital Melbourne:

Centre for Community

Child Health (blog), May

6,2019 , blogs.rch.org.au/

ccch/2019/05/06/theme-4-

evidence-for-innovation/.

\section{Recalibration: "We Can only Become Aware of the Features and Flaws of our Worldview in contrast with other Storglines" 18}

In 2011, Dr Linda Leach argued for the need to do more than pay lip service to diversity by simply situating it within the group. Leach asserted that indigenous peoples are still underrepresented in tertiary institutions and discussed the need to move away from methods that endorse "assimilation into the dominant culture." ${ }^{\prime 19}$ In 2016, outlining VUW's aims for the use of indigenous knowledge, Deputy Vice-Chancellor (Māori) Rawinia Higgins outlined, as part of a larger plan, a hybrid approach. "Màtauranga Māori and Mātauranga Pasifika (Māori and Pasifika knowledge) should not be confined to the pre-colonial era, because its evolution is also about knowledge interaction, production and hybridity."

In 2018, at the Design Research Society Conference in Limerick, Renata Leitão commented that discussions about culture and the cultural dimension in design were almost absent. Leitão noted the "Transition Design Provocation" assembled by Terry Irwin and her team of transition designers at Carnegie Mellon University, and Ezio Manzini within the Design for Social Innovation towards Sustainability network (DESIS) for acknowledging concerns around the continued use of Euro-American design edicts. Both consider these edicts to be limiting the possibility of social change and hindering the reconception of lifestyles that is required to combat the world's environmental, social, political, and economic predicaments (or "wicked problems"). ${ }^{21}$

As an extension of these thoughts, this study posits that paramount to the shift away from the standardization currently embedded in design education, the presence of and respect for indigenous students and indigenous knowledge is required. ${ }^{22}$ Sadly, "while there is increasing recognition in mainstream or Western settings of indigenous knowledge systems as legitimate in their own right, references to evidence-based practices and programs in policy and service settings still rarely include this type of knowledge." 23 


\section{"Mãori Should Stand Tall in the Eact That our Ancestors Led the World in Technology and Innovation, It's in Our DNA" ${ }^{24}$}

Leitão pointed out a fundamental flaw in contemporary design pedagogy when she stated that "the leading role of the modern man entails that we live on a planet with only one storyline: the heroic story of the modern man."${ }^{25}$

In New Zealand, design as a discipline developed well after the colonial period in the mid-twentieth century; as such, the design research and practice that was developed tended to sideline indigenous culture as having little to offer the discipline as future-focused, technologically advancing, and innovation orientated. This has resulted in current design pedagogy being dominated by a working model that privileges Western and capitalist influences. ${ }^{26}$ Although acknowledged as valuable to design, when diversity is explored as non-Western creative practice, quixotically it is still found to be sidelined within design curricula, which remain dominated by the Eurocentric, hegemonic, and linear (not circular) ideals. Considering the graphic, narrative, navigational, and technological innovations and accomplishments for which Māori are globally recognized, this sits awkwardly in the context of New Zealand design education.

At this point, this paper acknowledges the need for change as tacit, and introduces the recalibrated curriculum, course content, and student responses resulting from this undertaking. The first acknowledgment is of te ao Māori, the Māori worldview, that holds as its essence relationships - not just with people, but between the natural and spiritual worlds where both tangible and intangible relationships hold equal relevance and importance. ${ }^{27}$ As a part of this, tikanga (values) - which include manaakitanga (respect), akoranga (reciprocity), whanaungatanga (collaboration), kaitiakitanga (guardianship), and, importantly, rangatiratanga (self-determination) - act as protocols, behaviors, and beliefs that shape the past, present, and future lives of both people and place. Within the first-year and DSI programs we have engaged the ideology of connectedness imbued in te ao Māori and tikanga Māori to shape our three-year undergraduate curriculum structure, delivery modes,
24. Jacques-Pierre Dumas, IT Brief New Zealand (website), February 19, 2019, itbrief.co.nz (accessed January 10, 2020).

25. Leitão, "Recognising and Overcoming the Myths of Modernity."

26. Nan O'Sullivan, "Navigating Design History with a More Culturally Calibrated Compass," Journal of New Zealand Art, Media \& Design History 1, no. 3 (2017), 103-17.

27. Te Ahukaramū Charles Royal, "Te Ao Mārama: The Natural World," Te Ara: The Encyclopaedia of New Zealand (website), September 24, 2007, teara.govt.nz/en/teao-marama-the-natural-world (accessed October 29, 2019). 
and the diversity of those who deliver it, and reframed the course content and contexts to enable a number of approaches to be adopted that can impart indigenous knowledge to both students and staff.

\section{"Te Aha - Te Mea Nui - O Te Ao? He Tāngata, He Tāngata, He Tāngata" (What is the Most important Thing in the World? It is People, It is people, It is people)}

The first-year students who enroll at Te Kura Hoahoa, the School of Design Innovation are on average eighteen and a half years old when they commence studies. Having just left high school this is also quite possibly their first time living away from family (whanau). At the outset we aim to establish connections with the students, referencing people and place and, as importantly, emphasizing that education is a shared experience (whanaungatanga - from the root word whanau, "family"). Beyond the usual orientation activities, the school has introduced a digital experience to welcome and introduce students, and a curriculum framework that develops connection and curiosity (whai màtauranga) and builds confidence through respect (manaakitanga) and care (kaitiakitanga). This permeates into coursework that fosters a sense of identity, a capacity for empathy, and the capability of self-determination towards positive change within the fledging designers.

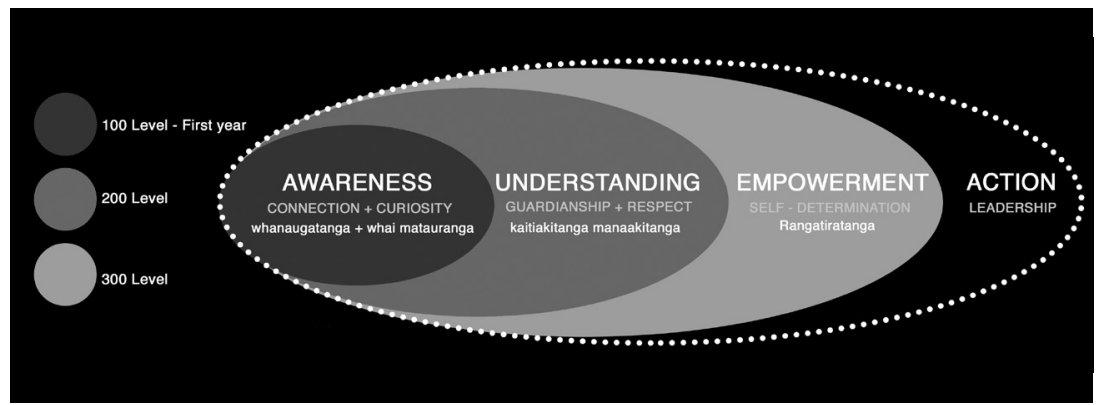

Growth of student capabilities throughout their undergraduate studies enabling them to identify and question, empathize and care for, and empower positive change both individually and collectively. 
Te Kuhunga (First Step; see www.firststep.fyi) is a website positions te reo Māori (Māori language) prominently within the text and discusses the use of tikanga Māori

(Māori protocols and values) throughout. The pages that receive the most hits are those concerning expectations and support. The school employs design students to assist in defining the aims and content, and yearly reviews are undertaken to ensure Te Kuhunga remains relevant and inclusive of their voice:

Help us, help you. In the spirit of whanaungatanga which means relationships and collaborations. Let's appreciate the shared experience of teaching and learning - talk about your mahi (work), korero (share your ideas) with your classmates and tutors and importantly, if you don't know something - JUST ASK! ${ }^{28}$

\section{A Curriculum Framework}

The initial aim of the curriculum is to enable the student to make connections between people and place, spark inquiry, and gain an ability to traverse new and often challenging knowledge. In the second year, students acquire important research and communication skills and are encouraged to discover, develop, and articulate their personal standpoints through their creative practice. Acknowledging kaitiakitanga (guardianship) and manaakitanga (respect and reciprocity), the students aim to be inclusive, sustainable, and sustaining in their design thinking and practice. The third-year curriculum encourages the volume in their voice. At this stage of the curriculum the coursework engages with real-world issues, at which point the more complex challenges around rangatiratanga (self-determination) begin. Rangatiratanga requires at its core a commitment to work with people and allow them to determine their own futures 


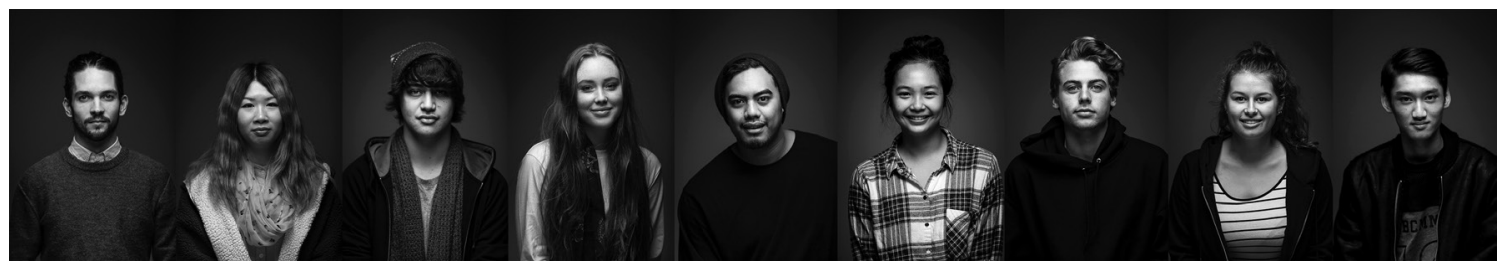

A reflection of the cultural diversity in the first year. Photo: St Andrew Matautia.

or outcomes. This is a significant shift away from designing for, i.e., designers imposing what they consider to be their "expert understanding" on others. As the number of graduates grows it is becoming important to ensure that connection, support, and learning can be ongoing. To that end, we are currently developing ways to stay tethered and ensure akoranga (a reciprocal knowledge-sharing relationship) develops as a continuously evolving and fluid loop between the programs, the alumni, and the contexts they work in.

\section{Coursework Permeated with Indigenous Knowledge}

Whanaungatanga: The first-year coursework specifically acknowledges familial and cultural relationships in order to encourage enjoyment and engagement within a collaborative learning environment. Drawing on their knowledge of symbolism, and with an understanding of te ao Māori, students reveal themselves through their culture or experiences of culture to express a personal narrative - a self-portrait through symbols. The aim is to encourage students to see themselves as a part of complex systems that connect people and place in many and varied ways. Using a combination of analog and digital software for pattern generation, students continued to expand on their understanding of iteration and connection (fig. 3). For some students this assignment is uncomfortable due to the introspection it requires. This experience can be difficult and at times confronting as students begin to recognize, investigate, or articulate such concepts. To mitigate this, the definition of culture is broadened to include other communities or groups that a student may identify with: LGBGT, feminism, and sports fan are all examples used by students. 
This project taught me about the importance of 'me' as part of my design work. I got a chance to communicate and work together with my family to discuss my heritage and to include my whänau (family) and our beliefs in my design work.

Kaitiakitanga (guardianship): The word kaitiakitanga holds specific relevance for the conversations of colonization within New Zealand's joint history with Māori, as it highlights fundamental cultural differences. As a part of te ao Māori, Māori consider themselves stewards of the land, sea, and sky. This is a relationship of guardianship, not ownership. This perhaps oversimplified explanation nevertheless offers an appreciation of just how differently Màori relate to the world's precious resources. Students are encouraged to consider the impact of their design work and to look at more contemporary considerations of sustainable and sustaining practice and outcomes in relation to kaitiakitanga. In a recent media promotion undertaken by Design Assembly, ${ }^{29}$ two SODI students were interviewed. When asked about what is important to them and what developments they wish to make in their work, they replied:

I need to continue to ask more questions and learn to listen and read the world and things around me a lot better. More specifically, I plan on exercising this by remaining connected to and learning more about my Māori heritage and from the people around $\mathrm{me}^{30}$
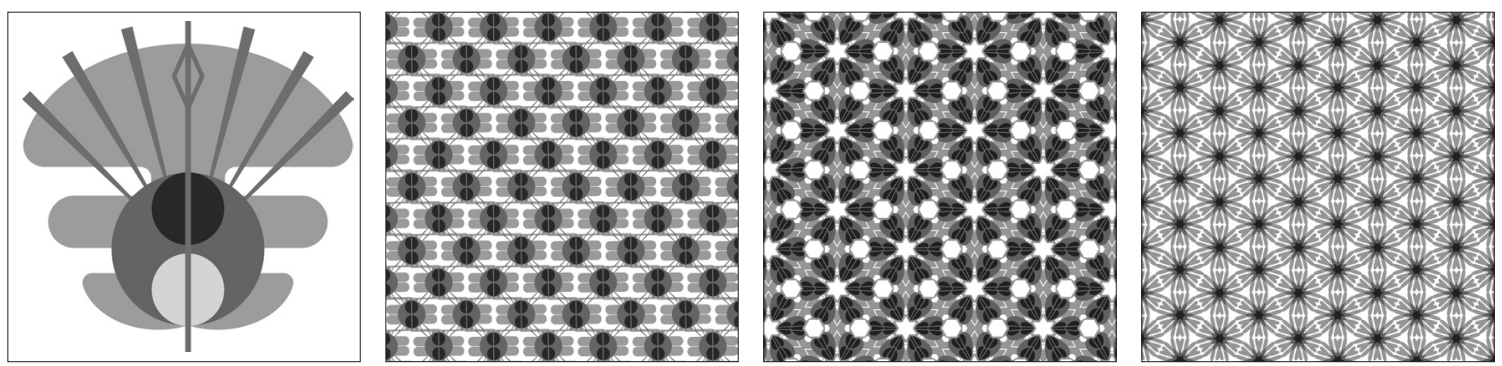

The individual symbols (top far left) are adaptations representing different degrees to which the individual feels a part of larger collectives. The first pattern expresses the student's relationship with their family or with their tutorial group of about 20 students. This student has located the symbol as a large and recognizable element within a group of similar elements. The second pattern represents the student within their class of 120 students. The pattern shows less distinction between each element, but its creator expressed in their reflective summary that the scale still enabled a place for individuality. The remaining patterns represent the symbol as a part of the entire first-year cohort of over 250 students who the student referred to as "kindred spirits."
29. Design Assembly is an independent and collaborative digital and physical platform for New Zealand visual designers to learn, keep up to date, and be inspired.

30. Louise Kellerman, Design Assembly (website), 2009, designassembly.org.nz (accessed January 13, 2020). 
I like to think critically about what I'm doing and why I'm doing it. Design isn't done in a vacuum; I think you have to really be present in the world and asking difficult questions to do well by other people as well as getting as much out of it as you can. The classes I've taken at Victoria have really pushed me in this sense. ${ }^{31}$

Rangatiratanga (self-determination): In a recent keynote at the World Design Assembly I spoke of the obstacles current design practice faces when engaging with selfdetermination. The example I gave was within the discipline's practices of codesign. Guided by tikanga Māori (Māori values) it was clear that certain approaches within design education, thinking, and practice require redress. The codesign and participatory approaches currently demonstrated within design speak to engagement, inclusion, equality, empathy, and more often than not produce "designed" outcomes "for" clients. Whare Tapa Wha, a holistic model of health and well-being designed by Sir Mason Durie in 1982, was used to illustrate an alternative approach. ${ }^{32}$ Importantly it was designed by Māori for Māori. Whare Tapa Wha moves away from Western health models in which services are delivered by "outsider" experts. The correspondences with the Western model of "designing by" and "designing for" are evident. Whare Tapa Wha is one of a number of Māori and Pasifika models that evoke whanaungatanga (collaboration), kaitiakitanga (guardianship), and rangatiratanga (self-determination) as key. Most importantly for design, this model places agency into the hands of those seeking it and ensures that decisions around stakeholder participation, methodology, evidence, intervention, communication, facilitation of outcomes, and distribution of funding are in the hands of those whose lives, lands, children, and grandchildren are to be impacted. This aspect of rangatiratanga is perhaps where design as a discipline still has work to do and is where we place the challenge for the students in our programs.

The goal of our endeavours is to enable a new generation of designers with a nuanced appreciation and respect for the connectivity and values imbued within 
indigenous knowledge and that have the skills and courage to engage empathy, care, respect, reciprocity, and autonomy as strategies to design with. This paper offers manaakitanga (respect for all that connects us), nga manakura (empathy towards all that connects us), and kaitiakitanga (guardianship of all that connects us) as new ways of being and designing more positive, inclusive, sustaining, and sustainable relationships between people and place.
32. Whare Tapa Wha (the four cornerstones) is a holistic strength-based model that considers wellbeing in terms of social, physical, mental, and spiritual capacities.
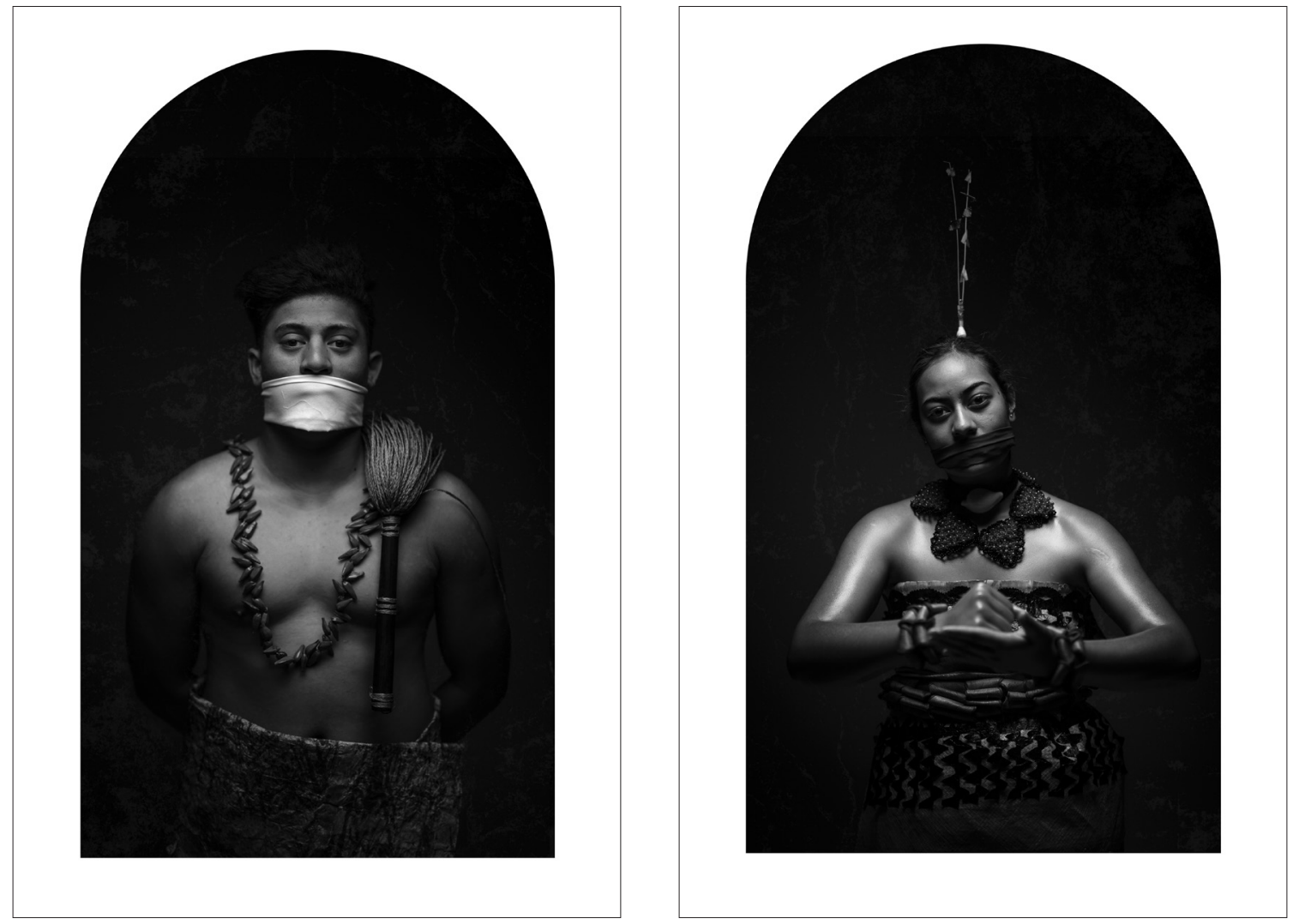
Davis, Katarina. Innovate Change. 2017. www.innivatechange.co.nz (accessed November 16, 2019).

Dumas, Jacques-Pierre. IT Brief New Zealand. February 19, 1919. itbrief.co.nz (accessed January 10, 2020).

Escobar, Arturo. "Transciones: A Space for Research and Design for Transitions to the Pluriverse." Design Philosophies Papers 13, no. 1 (2015), 13-23.

Gamble, Jamie, et al. The Royal Hospital Melbourne. 2018. blogs.rch.org.au/ ccch/2019/05/06/theme-4-evidence-forinnovation/ (accessed January 3, 2020).

Gattegno, Caleb. The Silent Way. New York: Education Solutions Worldwide Inc, 1963.

Higgins, Rawinia. "Contributions to the Growth and Development of Māori Matauranga." Enriching Cultural Heritage Symposium. Te Herenga Waka Wellington: Victoria University of Wellington, 2016.

Irwin, Terry, et al. "Transition Design

Provocation." Design Philosophies 13, no. 1 (2015), 3.

Kellerman, Louise. 2009. designassembly. org.nz. www.designassembly.com (accessed January 13,2020 ).

-. https://designassembly.org

nz/2020/01/07/hot-new-things-

2020-liliana-manetto-quick/. www. designassembly.com (accessed January 13 2020).

Leach, Linda. “'I Treat All Students Equal” Further and Higher Teachers' Responses to Diversity." Journal for Further and Higher Education 35 (2011), 247-63.

Leitão, Renata. "Recognising and

Overcoming the Myths of Modernity." In

Proceedings of Design Research Society Conference DRS 2018: Catalyst. Limerick: University of Limerick, 2018, 8.

Mead, Hiniri Moko. Tikanga Māori: Living by Māori Values. Wellington: Huia Publishers, 2003.

O'Sullivan, Nan. "Navigating Design History with a More Culturally Calibrated Compass." Journal of New Zealand Art Media and Design History 1, no. 3 (2017), 103-17.

-. "Constructing Your own Reality Prevents

Others from Doing It For You: A Shift towards

Cultural Inclusivity in Design." Cumulus

REDO Conference. Kolding: Design School

Kolding, 2018.

—. "Walking Backwards into the

Future:Indigenous Wisdom within Design

Education." Educational Philosophy and

Theory (Taylor and Francis Online) 51, no. 4

(2018), 424-33.

- , and David Hakaraia. firststep.

fyi/2019/01/11/expectations/. Faculty of

Architecture and Design. January 10, 2019.

www.firststep.fyi (accessed November 16. 2019).

Royal, Te Ahukaramū Charles. Te Ara: New Zealand Government. 2007. www.TeAra.govt. nz/en/te-ao-marama-the-natural-wprld/ page- (accessed October 29, 2019).
Statistics NZ. 2019. Stats NZ. New Zealand Government. 2019. www.stats.govt.nz. (accessed January 7, 2020).

Te Ripowai Higgins, and Meremoana Potiki. Tikanga Māori at Victoria. Cultural Capability, Centre for Academic Development, Victoria University of Wellington. Wellington: Victoria University of Wellington, n.d.

VUW Human Resources. Tikanga Māori at Victoria. Academic Development, Human Resources, Victoria University of Wellington. Wellington: Victoria University of Wellington, 2016.

VUW Senior Leadership Team. Strategic Plan. Strategic Policy, Victoria University of Wellington. Wellington: Victoria University of Wellington, 2014.

- The Treaty at Victoria VUW Investiment Plan (2015-2017). Strategic Investment, Victoria University of Wellington. Wellington: Victoria University of Wellington, 2015 26-27. 